\title{
Trabalhonecessário
}

Issn: 1808 - 799X

ano 13, número $22-2015$

\section{AS FEIRAS LIVRES COMO LUGARES DE PRODUÇÃO \\ COTIDIANA DE SABERES DO TRABALHO E EDUCAÇÃO \\ POPULAR NAS CIDADES: ALGUNS HORIZONTES TEÓRICOS E \\ ANALÍTICOS NO CAMPO TRABALHO-EDUCAÇÃO}

\section{Carolina Rezende de Souza ${ }^{1}$}

\section{Resumo}

Este artigo, pautado em uma revisão bibliográfica tem o objetivo de tecer horizontes teóricos e analíticos sobre as feiras livres, enquanto lugares de produção cotidiana de saberes do trabalho, vinculados à educação popular. Podese constatar, que as feiras livres, representam lugares de formação humana, de processos educativos e pedagógicos a partir da produção de saberes do trabalho, os quais devem ser reconhecidos e valorizados no universo acadêmico, especificamente no campo de estudos Trabalho- Educação.

Palavras-chave: Feiras Livres; Saberes do trabalho; Educação popular.

\begin{abstract}
This article, based on a literature review aims to weave theoretical and analytical horizons on the open markets as places of everyday production work knowledge, linked to popular education. It can be seen that free trade, are represented places of human, educational and pedagogical processes from the working knowledge production, which should be recognized and valued in the academic world, specifically in the field of work-education studies.
\end{abstract}

Keywords: Free trade shows; Knowledge of labor; Popular education.

\footnotetext{
${ }^{1}$ Bacharel em Ciências Sociais pela Pontifícia Universidade Católica de Minas Gerais. Mestre em Educação pelo Programa de Pós-Graduação/ Mestrado em Educação da Universidade do Estado de Minas Gerais (FAE/CBH/UEMG); (31) 9638-4867; E-mail: carolzitacs@hotmail.com.br
} 


\section{Trabalhonecessário}

Issn: 1808 - 799X

\section{Introdução}

ano 13, número $22-2015$

No contexto de muitas cidades, convivem, lado a lado, variadas formas de apropriação do espaço público, tendo em vista usos hegemônicos e não hegemônicos, que devem ser considerados em nossas análises e investigações acadêmicas, nos quais coexistem e interagem uma pluralidade de trajetórias e práticas cotidianas (Almeida, 2009), que dizem respeito a diferentes universos como o mundo do trabalho.

Neste sentido, nas diferentes cidades brasileiras, evidenciamos o trânsito entre as atividades dos dois circuitos da economia, que estão vinculadas ao mundo do trabalho urbano. O geógrafo Milton Santos (1979) refletindo sobre o processo de urbanização dos países subdesenvolvidos, discorre sobre os diversos tipos de atividades econômicas ocupacionais, existentes nestes universos. Para o autor, esse processo caracteriza-se pela divisão do espaço urbano em dois circuitos econômicos, que convivem de maneira bastante tensa. O circuito superior, para o autor, está relacionado com atividades econômicas ditas modernas, vinculadas à acumulação do capital, à existência dos grandes conglomerados, bem como pelo uso de tecnologia de ponta, e, por sua vez, o circuito inferior da economia, que se utiliza de tecnologia pouco sofisticada e vincula-se ao comércio das classes médias e populares, que garantem a sobrevivência destes atores sociais.

As feiras livres, que possuem uma importância cultural antiga, que remonta à história mundial, no Brasil tiveram origem ibérica, trazidas de Portugal, no período da colonização (Almeida, 2009; Lucena e Cruz, 2011; Matos, 2005). Atualmente, revelam-se práticas cotidianas de trabalho, inseridas no âmbito do circuito inferior da economia urbana, definido por Milton Santos (1979), que vivenciam marginalização pelo poder público, na medida em que são qualificadas como antiquadas, obsoletas e anacrônicas, por não estarem em compasso com a mundialização da economia, que criou novas formas de comercialização (Mascarenhas e Dolzani; 2008; Matos, 2005). 


\section{Trabalhonecessário}

Issn: 1808 - 799X

ano 13, número $22-2015$

Porém, apesar do cenário acima descrito, ainda possuem grande representatividade no universo urbano contemporâneo e devem ser reconhecidas e valorizadas, na medida em que continuam a impulsionar práticas cotidianas de trabalho de grupos populares e grupos subalternos (Mascarenhas e Dolzani, 2008; Matos, 2005) e, desta forma, relacionadas ao exercício da resistência cultural e da territorialidade (Mascarenhas e Dolzani, 2008) por parte destes atores sociais.

Nesta perspectiva, parte-se do pressuposto, neste artigo, que as feiras livres, para além da simples comercialização, compra e venda de mercadorias, devem ser pensadas enquanto espaços educativos e pedagógicos não formais de aprendizagem, que revelam a dimensão educativa das cidades e da relação do trabalho com a formação humana. Desta forma, tais lugares devem ser compreendidos, também, como espaços privilegiados de educação popular e de produção cultural (Dalenogare e Alberti, 2011), os quais trabalhadores e trabalhadoras criam e recriam, em suas práticas cotidianas, diferentes saberes do trabalho.

Neste sentido, reconhece-se a diversidade e complexidade dos processos educativos e pedagógicos engendrados no universo da Educação de jovens e adultos trabalhadores, aliado ao conceito de cidades educativas, buscando-se valorizar a pluralidade de tempos e espaços, onde a educação e a formação humana podem e devem ser pensadas em concomitância com a vida, com a cultura, com o mundo do trabalho e, neste sentido, com as diferentes relações, que os sujeitos estabelecem com o mundo e com o devir histórico como nos ensinam teóricos como Paulo Freire e Carlos Rodrigues Brandão.

Pode-se dizer que os processos pedagógicos não estejam reduzidos a meros sistemas e procedimentos de educação, ampliando-se, desta forma, os espaços de construção de conhecimentos válidos para além das instituições escolares. Deve-se acrescentar à reflexão sobre os sistemas e métodos, a dimensão sociocultural do valor desses modos de ensinar e aprender viabilizados 


\section{Trabalhonecessário}

Issn: 1808 - 799X

ano 13, número $22-2015$

no universo da cultura do trabalho nas feiras livres, que expressam a dimensão educativa das cidades acima mencionada.

Considerando-se todas as questões acima elencadas, este artigo, pautado em uma revisão bibliográfica ${ }^{2}$, tem o objetivo de tecer horizontes teóricos e analíticos sobre as feiras livres, enquanto lugares de produção de saberes do trabalho vinculados à educação popular e, desta forma, as contribuições de tais reflexões no que concerne ao campo de estudo acima mencionado. Para tanto, buscou-se a exposição de alguns estudos de caso em articulação com referenciais teóricos adotados e relacionados ao campo de estudos TrabalhoEducação, articulados ao conceito de cidades educativas, bem como ao aporte teórico de Carlos Rodrigues Brandão e Paulo Freire, sobre educação popular e as possibilidades destas análises teóricas e analíticas para problematizarmos 0 contexto das cidades brasileiras.

Pode-se constatar que trabalhadores e trabalhadoras urbanos, no universo das feiras livres constroem e reconstroem, cotidianamente, saberes ao longo de suas trajetórias de trabalho e histórias de vida, que devem ser valorizadas e legitimadas no universo deste campo de estudos. O trabalho desempenhado nas feiras livres, para além da simples compra, comercialização e venda de mercadorias, em como enquanto espaços educativos e pedagógicos não formais de aprendizagem, de formação humana e de educação popular, cujos trabalhadores e trabalhadoras criam e recriam saberes, a partir de suas estratégias de sobrevivência material e simbólica.

\footnotetext{
${ }^{2}$ Este artigo é fruto de reflexões e problematizações viabilizadas no universo da disciplina isolada Troca e reciprocidade, cursada no segundo semestre de 2014, no universo do Programa de PósGraduação em Antropologia Social da Universidade Federal de Minas Gerais (UFMG), ministrada pela professora doutora Deborah Lima.
} 


\section{Trabalhonecessário}

Issn: 1808 - 799X

ano 13 , número $22-2015$

\section{Um breve histórico das feiras livres, no mundo, no Brasil. Seu papel na contemporaneidade}

As feiras livres remontam o período da Antiguidade. Algumas fontes históricas dão conta da existência destas práticas entre os Astecas, os gregos e os romanos (Almeida, 2009). Elas adquiriram maior notoriedade no universo da revolução comercial do século $\mathrm{XI}$, na Idade Média, onde as mesmas foram oficializadas. (Almeida, 2009). Para Gonçalves \& Abdala (2013) estas práticas de trabalho revelaram seu auge no século $\mathrm{XI}$, na Europa, onde os mercados locais se organizavam como vistas a suprir a população com gêneros de primeira necessidade, o que evidencia que estas práticas surgiram com as primeiras aglomerações, povoados, vilas e posteriormente cidades.

No período da Idade Média, tendo em vista o desenvolvimento e aprimoramento de técnicas agrícolas nos feudos, a produção aumenta e um excedente é gerado e comercializado no universo das feiras (Reis e Vieira, 2011). Weber (1979) relaciona o aparecimento das cidades ao surgimento das feiras livres que possibilitaram atividades comerciais como as feiras que instigaram a abertura de estradas e comunicações entre os grupos. Com o ressurgimento do comércio e reabertura do Mar Mediterrâneo, aconteceu um período de renovação comercial na Europa. No período da Idade Média, tendo em vista o desenvolvimento e aprimoramento de técnicas agrícolas nos feudos, a produção aumenta e um excedente é gerado e comercializado no universo das feiras (Gonçalves e Abdala, 2013). Na Europa Medieval, as feiras livres constituíam-se espaços de sociabilidades, reunindo mercadores de diversas regiões, portos italianos, consolidando o comércio terrestre e mercados orientais de toda a Europa Ocidental (Gonçalves e Abdala, 2013).

No Brasil, as feiras livres datam do período colonial, sendo práticas trazidas e implantadas pelos colonizadores portugueses (Almeida, 2009; Lucena e Cruz, 2011; Mott, 2000). Matos (2005) nesta perspectiva, afirma que a feira livre se revelou presente na cultura popular brasileira, desde a época colonial, trazida 


\section{Trabalhonecessário}

Issn: 1808 - 799X

ano 13 , número $22-2015$

pelos portugueses. Para ele, as primeiras feiras se deram entre o século XVII e XVIII com o crescimento demográfico e diversificação da economia, sendo responsáveis pela formação e povoamento do interior brasileiro, onde posteriormente expandiram-se para todo 0 território e desempenhando importantes papeis no abastecimento das populações com os mais diversos produtos.

Atualmente, podemos considerar que, no cenário urbano contemporâneo, as feiras livres constituem alvo de críticas e marginalização pelo poder público, na medida em que são consideradas antiquadas e anacrônicas, face ao surgimento das grandes redes de hipermercados e dos automóveis, revelando-se assim, tradições urbanas tornadas obsoletas, por não estarem em compasso com as novas tendências econômicas, ditas mais lucrativas e mais seguras como as grandes redes de supermercados (Mascarenhas e Dolzani, 2008).

Para Matos (2005), as feiras livres se revelam na contemporaneidade, desprezadas pelo atual processo de mundialização da economia, face às novas formas e práticas de comercialização, engendradas a partir dos supermercados e shoppings centers. Jesus (2002; 2005) nesta perspectiva, reflete sobre imaginário social associado às feiras livres cariocas, no início do século $X X$, que comumente as vinculou à sujeira, à ilegabilidade, desordem, atraso e promiscuidade, que se contrapunham aos ideários modernizantes, marcados pelos novos padrões de beleza, higiene e civilidade.

A pesar do quadro acima descrito, as feiras livres resistem na paisagem urbana contemporânea de muitas cidades brasileiras, mesmo com a comodidade dos grandes hipermercados, higienizados e globalizados (Gonçalves e Abdala, 2013). Neste sentido, ainda resistem na paisagem urbana contemporânea, enquanto importantes locais de encontros, tradições e práticas com sentidos e significados nas trajetórias e cotidianos de diferentes atores sociais urbanos (Almeida, 2009).

Matos (2005) afirma que mesmo com a proliferação dos supermercados e dos shoppings centers nas grandes cidades, as feiras livres vêm persistindo 


\section{Trabalhonecessário}

Issn: 1808 - 799X

ano 13, número $22-2015$

principalmente nas periferias, não a penas como práticas e formas de permitir aos setores populares e subalternos formas de garantia de emprego e renda, mas também como espaços de sociabilidade, compra, venda e assim de trocas materiais e não comerciais, materiais e simbólicas. As reflexões de autores como Reis \& Vieira (2011), Sato (2007), Silva (2014) e Vedana(2004), também se revelam importantes para o entendimento do fato de as feiras livres ainda resistirem na paisagem urbana de nossas cidades, mantendo aspectos informais, pessoais e de grande interação entre diferentes atores sociais.

\section{O conceito de cidades educativas: algumas reflexões necessárias}

As cidades em muitos momentos foram vistas e analisadas a partir de perspectivas e pontos de vista reducionistas e reificadores que, muitas vezes, impediram o entendimento das práticas dos diferentes indivíduos e grupos sociais inseridos nestes universos. Araújo (2013) reflete sobre algumas análises, que naturalizam estes universos, pensados como espaços imutáveis, não como historicamente construídos, permeados por sentidos e significados, que devem ser valorizados, que obscurecem o desvelamento das múltiplas experiências de vida instauradas nestes espaços.

Nesta perspectiva, para além desta visão reducionista e, que naturalizam a investigação das cidades e, consequentemente, o desvelamento das práticas cotidianas e saberes de diferentes indivíduos e grupos sociais, como trabalhadores e trabalhadoras urbanos, é necessário o reconhecimento de suas dimensões educativas. Alguns autores, revelam-se fundamentais para a compreensão da dimensão educativa das cidades como Araújo (2013), Carrano(2003), Gadotti (2006), Miranda \& Blanch( 2013), Paulo Freire ( 2001), e Siman (2010).

Gadotti (2006) discorre sobre as cidades educadoras e educandas, onde as mesmas apresentam possibilidades educativas, capazes de proporcionar 


\section{Trabalhonecessário}

Issn: 1808 - 799X

ano 13, número $22-2015$

vivências, processos educativos e aprendizados significativos. Siman( 2010) reconhece o potencial educativo da cidade, em seu artigo Entre $o$ Asfalto e a terra: a fecundidade educativa do cotidiano poético da cidade, Siman(2010), onde assinala a importância da própria cidade ser tomada como objeto de problematização, destaca o potencial educativo do cotidiano da mesma. Para esta autora:

O cotidiano da cidade é mais do que uma história do banal, do corriqueiro, é mais do que transito intenso e apressado de mercadorias, dos seus transportes, dos homens sendo transportados individual ou coletivamente sobre o traçado físico da cidade. A história que se vive no cotidiano da cidade é efeito material e simbólico desses movimentos reveladores de sentidos do pensar e agir dos homens em suas múltiplas relações sociais, tecidas em diferentes lugares. (Siman, 2010, p.583).

Miranda \& Blanch(2013) consideram o potencial educativo das cidades em uma perspectiva ampla, que valoriza e reconhece as ações intencionalmente exercidas sobre o espaço público escolar como não escolar, enquanto universos, que devem ser pensados na sua multiplicidade e pluralidade, marcados por várias experiências sociais, formas de sensibilidade, temporalidades e experiências sociais. Araújo (2013), opondo-se a visões naturalizantes e reificadoras sobre as cidades. Reconhece, que ela deve ser pensada em suas dimensões educativas, tomando seu potencial educativo, a partir da valorização de suas dimensões materiais e simbólicas, múltiplas significações, memórias, experiências coletivas e temporalidades.

Carrano (2003), nesta mesma direção, reflete sobre a necessidade de compreender as dimensões educativas das cidades como uma esfera da educação ampliada, que se processa na heterogeneidade de espaços sociais praticados nas diferentes atividades desenvolvidas, que não são necessariamente vividas em contextos institucionais concebidos para educar, pensando-se os processos formativos, através de inúmeras práticas, que ocorrem no próprio movimento da vida e das práxis social. 


\section{Trabalhonecessário}

Issn: 1808 - 799X

ano 13 , número $22-2015$

Paulo Freire (2001) também apresenta contribuições sobre a dimensão educativa das cidades, a partir de suas reflexões sobre as dimensões educativas das experiências urbanas, nas suas diferentes ações desenvolvidas por diversos atores sociais, para além dos espaços escolares, em processos que se caracterizam por uma educação permanente de ensinantes e aprendizes, na sua relação com a vida, corpo, tradições, história, com a práxis social, nas suas dimensões éticas, estéticas, urbanísticas e ecológicas.

Paulo Freire (2001) sobre a dimensão educativa das cidades:

Não basta reconhecer que a cidade é educativa, independente de nosso querer ou de nosso desejo. A cidade se faz educativa pela necessidade de educar, de aprender, de ensinar, de conhecer, de criar, de sonhar, de imaginar que todos nós: mulheres e homens impregnamos suas ruas, suas praças, suas fontes, suas casas, seus edifícios, deixando em tudo, o selo de certo tempo, o estilo, o gosto de certa época. A cidade é cultura, criação, não só pelo que fazemos nela e dela, pelo que criamos nela e com ela, mas também é cultura pela própria mirada estética ou de espanto, gratuita, que the damos. A cidade somos nós e nós somos a cidade. (Freire, 2001, p.13).

\section{As feiras livres como lugares de produção cotidiana de saberes do trabalho e educação popular: algumas contribuições teóricas e analíticas ao campo Trabalho-Educação}

A compreensão das feiras livres como lugares de produção de saberes do trabalho traz a necessidade de análise e aprofundamento, acerca da subjetividade das relações no/com o lugar. Para Carlos (2007), os lugares exprimem-se pelas relações, que os indivíduos mantêm com os espaços habitados evidenciados nos modos de uso, nas condições mais banais, sentidos pensados, apropriados e vividos através do corpo, onde se processa a vida. Nesta mesma perspectiva, para Ludwig (2008) o lugar é dotado de significados para aqueles que o vivenciam, que tem particularidades históricas, por meio das quais se 


\section{Trabalhonecessário}

Issn: 1808 - 799X

ano 13 , número $22-2015$

desenvolveu um modo de vida especifico, de acordo com a organização social e cultural, levando-se em consideração sua inserção na sociedade global.

Nesta mesma perspectiva, o lugar antropológico para Marc-Augé (2004) define- se como identitário, relacional e histórico. Identitário, porque é o lugar de nascimento, as regras de residência são como uma inscrição no solo, que compõe a identidade individual. Referências compartilhadas, que designam fronteiras, marcam a relação com seus próximos e com os outros. Por fim, é histórico na medida em que os nativos vivem na história (Augé, 2004).

Desta forma, as feiras livres, sobretudo no universo de cidades brasileiras, devem ser pensadas como importantes lugares onde são produzidos, cotidianamente, saberes do trabalho, caracterizados por atos, gestos, performances corporais, movimentos e dizeres, formas de agir e se relacionar fomentadas por feirantes e fregueses, onde se ergue uma rede de sociabilidades vivenciadas pelos atores sociais no âmbito desses territórios construídos e reconstruídos cotidianamente (Vedana, 2004).

A cidade se faz educativa em diferentes contextos e universos como o trabalho nas feiras livres. Trabalho este, que deve ser pensado em suas dimensões educativas e de formação humana de diferentes indivíduos e grupos sociais. Ao considerar o trabalho nas feiras livres como lócus de produção e mobilização de saberes, é relevante problematizá-lo na sua relação com os processos educativos e com a formação humana. Para Marx (2010) o trabalho revela-se uma atividade especificamente humana e central na produção da vida, relacionada à apropriação da natureza e a processos de constante criação da vida em suas múltiplas e históricas necessidades.

Paulo Freire (1989) enfatiza estas discussões na medida em que considera o homem como um ser no mundo, com o mundo e com o outro, enquanto seres criadores e recriadores da realidade, através do trabalho, diante de suas necessidades e de promoção de sua sobrevivência. Para este autor, através do trabalho, o homem transforma a matéria da natureza, produz cultura, história e a 


\section{Trabalhonecessário}

Issn: 1808 - 799X

ano 13, número $22-2015$

sua própria existência. Schwartz (2003), nesta mesma direção, considera que nós produzimos nossa própria existência na atividade de trabalho.

Desta forma, reconhecer o trabalho como educativo e de relação na formação humana dos diferentes indivíduos e grupos sociais, implica desvelar e descortinar os processos de produção e mobilização de saberes, que circulam e permeiam as diferentes situações de trabalho. Sob esta perspectiva e, mais do que isto, a partir de posturas epistemológicas e ontológicas, que fogem dos padrões tradicionais, estes atores sociais passaram a ser reconhecidos e valorizados como sujeitos produtores de conhecimento e do saber como destaca Aranha (2003).

Dentre os estudos e problematizações já realizadas a respeito da produção, mobilização e circulação de saberes nas diferentes situações de trabalho, podemos destacar as realizadas por autores como Aranha (1997; 2000; 2003), Charles Cunha (2013), Cunha e Schwartz (2006), Daisy Cunha (2009); Eloisa Helena Santos (1983; 1997; 2000), Lima, Petrus e Cunha (2013), e Schwartz (2001; 2003).

Neste sentido, revela-se de extrema importância o reconhecimento da dimensão educativa nas cidades, a partir da valorização de lugares não formais de ensino e aprendizagem como as feiras livres, ainda não problematizados do ponto de vista teórico e acadêmico no campo de estudos Trabalho- Educação, os quais, para além da simples comercialização e compra de mercadorias, o caráter educativo e de formação humana do trabalho se faz presente na luta cotidiana, pela sobrevivência material e simbólica por parte de trabalhadores e trabalhadoras urbanos e, assim, pode e deve ser tomado como centralidade para a compreensão da produção cotidiana de saberes, na complexidade dos projetos, trajetórias e histórias de vida destes atores sociais, na dialética do passado, presente e futuro (Charlot, 2000; 2001; Santos, 1983; 1997; 2000).

Através destas reflexões, ressaltamos que a valorização do caráter educativo e de formação humana do trabalho desempenhado nas feiras livres, na sua relação com a educação popular e no campo de estudos acima mencionado, 


\section{Trabalhonecessário}

Issn: 1808 - 799X

ano 13, número $22-2015$

a partir do reconhecimento da produção cotidiana de saberes nestes espaços torna-se fundamental para o resgate do valor epistemológico, social, econômico, político e cultural dos saberes dos sujeitos inseridos nas diferentes situações de trabalho (Santos, 1997). Importante, também, para o reconhecimento dos trabalhadores e trabalhadoras urbanos no cenário acadêmico, a partir de novas posturas ontológicas e epistemológicas, que valorizam estes atores sociais como sujeitos do conhecimento e do saber (Aranha, 2003).

É importante considerar que a produção de saberes no universo do trabalho nas feiras livres remete-nos ao entendimento e compreensão da emergência da subjetividade dos trabalhadores e trabalhadoras, expressas nas relações que estes atores sociais estabelecem com o saber. Para Charlot (2000; 2001), toda a relação com o saber também é relação com o mundo, com o que aprende e com ele mesmo. Segundo este autor, aprender torna-se uma atividade humana de engajamento e, assim, envolve processos e movimentos singulares, porque são desenvolvidos por sujeitos, suas subjetividades, histórias, projetos e trajetórias, estruturados por relações sociais, na dinâmica do tempo passado, presente e futuro.

Eloisa Helena Santos $(1983 ; 1997 ; 2000)$ é uma autora cujas reflexões revelam-se fundamentais, na medida em que se utiliza da noção de relação deste teórico em suas problematizações, ela destaca que os sujeitos trabalhadores constroem diferentes relações com o saber, caracterizadas e permeadas por sentidos e valores, que estes atores sociais atribuem ao saber e, onde, mais do que isto, mobilizam suas subjetividades, em consonância com as suas histórias, suas trajetórias pessoais, desejos e vontades articuladas com seus projetos de vida e suas condições de existência.

Considerando-se todas estas questões, podemos afirmar que, as diferentes experiências engendradas no universo do trabalho urbano desempenhado nas feiras livres, mostram-se como fundamentais na constituição de processos educativos e pedagógicos, a partir da produção cotidiana de saberes do trabalho, que trazem à baila diferentes estratégias de sobrevivência material e simbólica 


\section{Trabalhonecessário}

Issn: 1808 - 799X

ano 13, número $22-2015$

engendradas por estes atores sociais, como nos apontam horizontes teóricos e analíticos os estudos e pesquisas desenvolvidas por autores como Almeida (2009), Lucena e Cruz (2011), Silva (2014) e Vedana (2004) que merecem ser mencionados.

Almeida (2009) em sua dissertação de mestrado intitulada Fazendo a feira: Estudo das artes de dizer, nutrir e fazer etnomatemático de feirantes e fregueses da Feira Livre do Bairro Major Prates em Montes Claros - MG, defendida no universo do Programa de Pós=Graduação em Desenvolvimento Social da Universidade Estadual de Montes Claros, demonstra como as feiras livres são lugares de produção de práticas pedagógicas e educativas, a partir da produção de saberes do trabalho, relacionados a saberes e fazeres negociados cotidianamente, expressos nas artes de dizer (jocosidades, performances e jogos corporais para atrair clientes), as artes de nutrir (gestos de manipulação da matéria, tais como o toque, a degustação) e nas artes de fazer evidenciadas em estratégias de calcular, estimar trocos, realizar medições, portanto, em manifestações matemáticas praticadas cotidianamente por meio de operações contextuais, eficientes, inclusive para pessoas sem o domínio da leitura e da escrita, como formas, que reinventam as clássicas fórmulas matemáticas, a partir das suas práticas sócio-educativo-econômico-culturais (ALMEIDA, 2009).

Lucena e Cruz (2012) em seu artigo Lugares que educam: o aprendizado nas feiras livres também refletem sobre a dimensão educativa e pedagógica evidenciada no trabalho nas feiras livres, a partir da constatação da produção e mobilização cotidiana de saberes do trabalho, relacionados ao trato com os números (contagem, as quatro operações: soma, subtração, divisão e multiplicação, e a porcentagem, entre outros), o desenvolvimento das relações interpessoais frutos das negociações, do trato e do talento para lidar com os clientes, o conhecimento do peso e medida das mercadorias, bem como o desenvolvimento da sensibilidade de reconhecer a qualidade de um produto.

Silva (2014) na sua dissertação de mestrado A Pedagogia da Feira Livre de São Bento: narrativas, saberes e práticas educativas na cidade de Cascavel - 


\section{Trabalhonecessário}

Issn: 1808 - 799X

ano 13, número $22-2015$

$C E$, defendida no Programa de Pós-Graduação em Educação Brasileira da Universidade Federal do Ceará, também apresenta contribuições ao refletir sobre a produção cotidiana de saberes no trabalho nas feiras livres, relacionados à habilidades com o dinheiro, o conhecimento sobre comércio, o domínio das operações da matemática, nas habilidades de resolver problemas operacionais, bem como no estabelecimento de relações sociais e de convivência com diferentes atores sociais.

Vedana (2004) em sua dissertação de mestrado intitulada Fazer a feira: estudo etnográfico das artes de fazer de feirantes e fregueses da Feira livre da Epatur, defendida no Programa de Pós-Graduação em Antropologia Social da Universidade Federal do Rio Grande do Sul (UFRS) também problematiza sobre a produção dos saberes no trabalho, no contexto da paisagem urbana de Porto Alegre, revelados a partir das artes de nutrir (gestos de manipular a matéria) e artes de dizer ( jocosidades, performances e jogos corporais para atrair clientes), que dizem respeito à práticas sociais de estetização do espaço das cidades por atores sociais como feirantes e fregueses.

Diante disto, podemos considerar, que a educação popular faz-se presente nas práticas das feiras livres, na medida em que estes trabalhadores e trabalhadoras, na luta cotidiana por melhores condições de sobrevivência material e simbólica, constroem e reconstroem saberes e, neste sentido, processos pedagógicos e educativos engendrados no universo de suas experiências socioculturais concretas, nas interações que estabelecem com o outro, com o mundo da vida e no mundo do trabalho como nos ensinam autores como Carlos Rodrigues Brandão (1981; 1985; 1995) e Paulo Freire (1989; 1999; 2011).

Por fim, é importante salientar, também, que estes saberes produzidos no universo da experiência do trabalho das feiras livres, vinculados à educação popular devem ser pensados no movimento e na dinâmica dos patrimônios e experiências vividas por estes atores sociais (Cunha, 2013; Cunha e Schwartz, 2006). E assim, na dialética do enraizamento, do desenraizamento (Weil, 1996), do externo, do interno, do novo, do velho (Santos, 1994), da dominação, da 


\section{Trabalhonecessário}

Issn: 1808 - 799X

ano 13, número $22-2015$

resistência cultural, da memória da própria cidade, que se transforma ao longo do tempo, das transformações evidenciadas no mundo do trabalho a nível local e global, bem como dos impactos decorrentes de fenômenos como a industrialização e a urbanização da própria sociedade brasileira (Soares, 2012).

\section{Considerações finais}

As feiras livres no contexto de muitas cidades no Brasil ainda apresentam no universo contemporâneo papeis fundamentais na geração de renda, promoção da segurança alimentar, da agricultura familiar, sociabilidade, identidade cultural e de construção de territorialidades. Neste sentido, é de extrema relevância, pensarmos as feiras livres, sobretudo no universo das cidades brasileiras, enquanto espaços de construção cultural, de territorialidades por parte de trabalhadores e trabalhadoras, que se revelam importantes lugares de comercialização e venda de mercadorias, mas também onde são viabilizadas práticas educativas e pedagógicas, vinculadas à educação popular e de produção de saberes do trabalho, que necessitam ser problematizados no universo acadêmico, principalmente no campo Trabalho- Educação, considerando-se a inexistência de estudos acadêmicos, que objetivam a investigação desta temática.

Os estudos apresentados a partir de uma pesquisa bibliográfica, articulados com o aporte teórico utilizado e o aporte teórico da educação popular de Paulo Freire e Carlos Rodrigues Brandão, possibilita-nos pensar as feiras livres como contextos e universos preciosos para a pesquisa acadêmica e a investigação no campo de estudos Trabalho-Educação, que devem ser valorizados e, mais do que isto, deve-se estimular a permanência de atividades tão antigas que ainda resistem e lutam, para sobreviverem no contexto da contemporaneidade e, que mais do que nunca assumidos em nossas investigações acadêmicas, a partir do reconhecimento de suas dimensões educativas e pedagógicas. 


\section{Trabalhonecessário}

Issn: 1808 - 799X

ano 13, número $22-2015$

Neste sentido, o reconhecimento das feiras livres como lugares de produção saberes do trabalho, vinculados à educação popular apresenta contribuições, que devem ser ressaltadas na promoção dos direitos subjetivos e coletivos, a partir do acolhimento e reconhecimento da diversidade cultural em universos como as cidades. Assim sendo, espera-se sejam estimulados estudos sobre as feiras livres no campo de estudos Trabalho-Educação, que possam garantir a efetivação democrática de direitos e assim, a promoção da diversidade cultural no universo das cidades, através do reconhecimento das práticas destes sujeitos socioculturais e históricos no universo de nossas investigações e pesquisas acadêmicas e de promoção da melhoria das condições de vida, trabalho, educação, bem como de afirmação das identidades individuais e coletivas, para além dos estereótipos e estigmas comumente associados a estes atores sociais.

\section{Referências}

ALMEIDA, Shirley Patrícia Nogueira de Castro e. Fazendo a feira: estudo das artes de dizer, nutrir e fazer etnomatemático de feirantes e fregueses da Feira Livre do Bairro Major Prates em Montes Claros - MG. 2009. 135f. Dissertação (Mestrado em Educação). Universidade de Montes Claros. Programa de PósGraduação em Desenvolvimento Social. Montes Claros-MG, 2009.

ARANHA, Antônia Vitória Soares. O conhecimento tácito e a qualificação do trabalhador. Trabalho e Educação, Belo Horizonte, NETE/FaE/UFMG, n.2, p. 1229, ago./dez.1997.

Relação entre o conhecimento escolar e o conhecimento produzido no trabalho: dilemas da educação do adulto trabalhador. Trabalho e Educação, Belo Horizonte, NETE/FaE/UFMG, v.12, p.103-114, jan./jun.2003.

ARAÚJO, Vanessa Barboza. A leitura da cidade e o desenvolvimento da consciência da cidade, p. 93-113. In: Sonia Regina Miranda; Lana Mara Castro Siman. (Org.). Cidade, Memória e Educação. 1ed. Juiz de Fora: EDUFJF, 2013, v. 1, p. 41-58.

AUGÉ, Marc. Não lugares: introdução a uma antropologia da supermodernidade. São Paulo: Papirus, 2004.220p.

BRANDÃO, Carlos Rodrigues. O que é Educação. São Paulo: Editora Brasiliense, 1981. 


\section{Trabalhonecessário}

Issn: 1808 - 799X

ano 13 , número $22-2015$

BRANDÃO, Carlos Rodrigues. A educação como cultura. São Paulo, Brasiliense, 1985.

BRANDÃO, Carlos Rodrigues. Em Campo Aberto: escritos Sobre a Educação e a Cultura Popular. São Paulo: Cortez, 1995.

CARLOS, Ana Fani Alessandri. O Espaço Urbano: Novos Escritos sobre a Cidade. São Paulo: FFLCH, 2007, 123p.

CARRANO, Paulo César Rodrigues. Juventudes e cidades educadoras. Petrópolis: Vozes, 2003.

CHARLOT, Bernard. Da relação com o saber: elementos para uma teoria. Porto Alegre: Artmed, 2000.

CHARLOT, Bernard. A noção de relação com o saber: bases de apoios teóricos e fundamentos antropológicos. In: CHARLOT, Bernard (Org). Os jovens e o saber, perspectivas mundiais. Porto Alegre: Artmed, 2001, p. 15-31.

CUNHA, Daisy Moreira. Lições de pedra: das minas de saberes e valores. Educação Unisinos, São Leopoldo, v.13, n.3,228-235, set / dez. 2009.

CUNHA, Charles Moreira. Saberes no trabalho: entre experiências e memórias: reflexões iniciais. Trabalho e Educação, Belo Horizonte, v.22, n.3, 209-222, set./dez. 2013.

CUNHA, Daisy Moreira; SCHWARTZ, Yvez A formação humana entre o conceito e a experiência do trabalho: elementos para uma pedagogia da atividade. Trabalho e Educação, Belo Horizonte, NETE/FaE/UFMG, v.15, n.1, 87-90, jan/jul.2006.

DALENOGARE, Vanessa; ALBERTI, Dirceu Luiz. Educação popular: saberes entrelaçados. Vivências: Revista Eletrônica de Extensão da URI, Erechim, Rio Grande do Sul, v.7, n.12,p. 1-8, maio.2011.

FREIRE, Paulo. Pedagogia do oprimido, 17ª . ed. Rio de Janeiro, Paz e Terra, 1988

FREIRE, Paulo. A importância do ato de ler: em três artigos que se completam / Paulo Freire. -. São Paulo: Autores Associados: Cortez, 1989.

FREIRE, Paulo. Educação como prática da liberdade. $23^{a}$ ed. Rio de Janeiro: Paz e Terra, 1999.

FREIRE, Paulo. A Educação na Cidade. 5 Edição. São Paulo: Editora Cortez, 2001.

FREIRE, Paulo. Pedagogia da autonomia: saberes necessários à prática educativa. 43. ed., São Paulo: Paz e Terra, 2011.

GADOTTI, Moacir. Cidade educadora e educanda Revista Pátio, ano X, oo 39, agosto/out, 2006, Uniararas, Araras, São Paulo.

GONÇALVES, Alexandre Oviedo; ABDALA, Mônica Chaves. 'Na banca do 'seu' Pedro é tudo mais gostoso' - Pessoalidade e sociabilidade na feira-livre. Ponto.Urbe (USP) , v. 2, p. 1-7, 2013.

JESUS, Gilmar Mascarenhas de. Ordenando o espaço público: a criação das feiras livres na cidade do RJ. Scripta Nova. Revista Eletrônica de Geografia y Ciencias Sociales. Universidade de Barceona, v.8, n.194, Agosto de 2005, p. 3045. 


\section{Trabalhonecessário}

Issn: 1808 - 799X

ano 13, número $22-2015$

JESUS, Gilmar Mascarenhas de. Negociando os usos e sentidos da rua: trajetória e representações da feira livre carioca. In: CARRERAS, C.; PACHECO, S. M. M. (Orgs.). Cidade e comércio: a rua comercial na perspectiva internacional. Rio de Janeiro: Armazém das Letras, 2009.

LIMA, Natália Valadares; PETRUS, Ângela Márcia Ferreira; CUNHA, Dayse Moreira; A produção de saberes no trabalho: qual o valor dos saberes investidos? Revista Pedagógica, Chapecó, v.15, n.31, p.322-334, jul./dez. 2013.

LUCENA, Thiago Isaias Nobrega de; CRUZ, Dalcy da Silva. Lugares que educam: o aprendizado nas feiras livres. Revista Interle-gere, Natal, Rio Grande do Norte, n.8, p.1-13, jan/jun.2011.

LUDWIG, Marcia Pinheiro. Para além da paisagem: a modernidade que ameaça submergir o lugar. In: ROTHMAN, Franklin. (Ed.). Vidas alagadas: conflitos socioambientais, licenciamento e barragens. Viçosa-MG: UFV, 2008. p. 235-253.

MARX, Karl. O Capital. São Paulo: Centauro Editora, 2010.

MASCARENHAS, Gilmar; DOLZANI, Mirian C.S; Feira livre: territorialidade popular e cultura na metrópole contemporânea. Ateliê Geográfico, Goiânia-GO, v.2, n.4, p.72-87, agos. 2008.

MATOS, Benedito Erivaldo de Souza. O centro da periferia: um recorte espacial da feira livre do Pedregal. Distrito Federal. (IH/GEA/UnB, Licenciatura. Geografia, 2012). Monografia, Trabalho Final em Geografia II. Universidade de Brasília. Instituto de Ciências. Departamento de Geografia. 2012, 42 p.

MIRANDA, Sônia Regina; SIMAN, Lana Mara Castro. A cidade como espaço limiar: sobre a experiência urbana e sua condição educativa, em caminhos de investigação. In: Sonia Regina Miranda; Lana Mara Castro Siman. (Org.). Cidade, Memória e Educação. 1ed. Juiz de Fora: EDUFJF, 2013, v. 1, p. 41-58.

MOTT, Luiz. Feiras e Mercados: Pistas para pesquisa de campo. In: FERRETI, SERGIO. (Org.). Reeducando o Olhar: Estudos sobre Feiras e Mercados, São Luiz: Edições Universidade Federal do Maranhão, 2000, v., p. 13-34.

REIS, Fernanda; VIEIRA, Soraya Maria Ferreira. Tudo Junto: pessoas, relações e peculiaridades na feira livre de Viçosa. In: ANAIS. Intercom - Sociedade Brasileira de Estudos Interdisciplinares da Comunicação XVIII Prêmio ExpocomExposição da Pesquisa Experimental em Comunicação, 2011. Disponivel em: $<$ www.intercom.org.br/papers/regionais/sudeste2011/.../EX24-0620-1.pdf > Acesso em: 15/05/2015.

SANTOS, Eloísa Helena. Ciência e cultura: uma outra relação entre saber e trabalho. Caderno de Serviços Sociais da PUC, Belo Horizonte, v.1, n.1, p. 12029, jul.1983.

SANTOS, Eloísa Helena. Trabalho prescrito e real no atual mundo do trabalho. Trabalho e Educação, Belo Horizonte. FAE/UFMG, v.12, n.1, p. 14-27, jan/jun.1997.

SANTOS, Eloísa Helena. A produção do Saber e sua Legitimação Política. In: Outras Falas. Revista de Formação Escola Sindical 7 de Outubro/CUT, n. 3. Belo Horizonte: Escola Sindical 7 de Outubro-CUT, agosto, 2000. 


\section{Trabalhonecessário}

Issn: 1808 - 799X

ano 13 , número $22-2015$

SANTOS, Milton. 0 espaço dividido: os dois circuitos da economia urbana dos países subdesenvolvidos. Rio de Janeiro: Francisco Alves, 1979. (Ciências Sociais).

SANTOS, Milton. A Natureza do Espaço: Técnica e Tempo, Razão e Emoção. 4. ed. 2. reimpr - São Paulo: Editora da Universidade de São Paulo, 1994.

SATO, Leny. Processos cotidianos de organização do trabalho na feira livre. Psicol. Soc. [online], v.19, n.spe, pp. 95-102, 2007.

SCHWARTZ, Yves. Entrevista: Trabalho e Educação. Presença Pedagógica, Belo Horizonte, v.7, n.38, p.5-17, mar./abr. 2001. (Realização, tradução e apresentação: Eloísa Helena Santos e Daisy Moreira Cunha).

SCHWARTZ, Yvez. Trabalho e saber. Trabalho e Educação, Belo Horizonte. NETE/FaE/UFMG, v.12, n.1, p.21-34, jan/jun. 2003.

SILVA, Francisca Eliana Santos da. A "Pedagogia" da Feira Livre de São Bento: narrativas, saberes e práticas educativas na cidade de Cascavel . 2014, 100f. Dissertação (Mestrado) - Universidade Federal do Ceará, Programa de Pósgraduação em Educação Brasileira, Fortaleza (CE), 2014.

SIMAN, Lana Mara de Castro. Entre o asfalto e a terra: a fecundidade educativa do cotidiano poético da cidade. In - DALBEN, Ângela Imaculada Loureiro de Freitas Et al. (Orgs.). Convergências e tensões no campo da formação e do trabalho docente. Belo Horizonte, Autêntica, 2010, SOARES, Pedro Paulo de Miranda Araújo. Saberes, fazeres e memória coletiva: a trajetória social de barbeiros e barbeiras da Região Central de Porto Alegre (RS). Iluminuras, Porto Alegre, v.13, n. 30, p. 260-279, jan./jun. 2012.

VEDANA, Viviane. "Fazer a feira": estudo etnográfico das -artes de fazer de feirantes e fregueses da feira livre da Epatur no contexto da paisagem urbana de Porto Alegre. Dissertação (Mestrado). Programa de Pós-Graduação em Antropologia. Universidade Federal do Rio Grande do Sul. 2004. 251p.

WEBER, Marx. Conceitos e categorias da Cidade. In: O Fenômeno Urbano, Otávio Velho (organizador). Rio de Janeiro: Zahar Editores, 1979.

WEIL, Simone. O enraizamento. In: A condição operária e outros estudos sobre a opressão. Antologia organizada por Ecléa Bosi. 2.ed.. Rio de Janeiro, Paz e Terra, 1996, p. 411-412.

Recebido em: 21 de setembro de 2015.

Aprovado em: 09 de dezembro de 2015. 